\title{
Impact of COPD Exacerbations on Osteoporosis Assessed by Chest CT Scan
}

\author{
Hirofumi Kiyokawa ${ }^{1}$, Shigeo Muro' ${ }^{1}$, Tsuyoshi Oguma ${ }^{1}$, Susumu Sato ${ }^{1}$, Naoya Tanabe ${ }^{1}$, Tamaki Takahashi ${ }^{1}$, \\ Megumi Kudo ${ }^{1}$, Daisuke Kinose ${ }^{1}$, Hiroshi Kondoh' ${ }^{2}$, Takeshi Kubo ${ }^{3}$, Yuma Hoshino ${ }^{1}$, Emiko Ogawa', \\ Toyohiro Hirai ${ }^{1}$, and Michiaki Mishima ${ }^{1}$
}

1 Departments of Respiratory Medicine, Kyoto University, Kyoto, Japan

2 Geriatric Medicine, Graduate School of Medicine, Kyoto University, Kyoto, Japan

3 Department of Diagnostic Imaging and Nuclear Medicine, Kyoto University, Kyoto, Japan
Keywords: Exacerbation, Osteoporosis, Bone mineral density, Chronic obstmetive pulmonary disease, Emphysema.

Correspondence to: Shigeo Muro Department of Respiratory Medicine, Graduate School of Medicine Kyoto University 54 Kawahara-cho, Shogoin, Sakyo-ku Kyoto 606-8507 Japan phone: +81 757513830 fax: +81 757514643 , email: smuro@kuhp.kyoto-u.ac.jp

\begin{abstract}
Background: COPD pathology involves not only the lungs but also extrapulmonary abnormalities. Osteoporosis is one of the most important abnormalities because it may cause vertebral compression fractures and deteriorate pulmonary function. COPD patients have many risk factors for osteoporosis, such as low BMI, decreased activity, systemic inflammation, and use of corticosteroids. Some of these factors have been shown to deteriorate with COPD exacerbations. We previously demonstrated the correlation between emphysema and osteoporosis and between emphysema progression and COPD exacerbations. Thus, the hypothesis that exacerbation causes osteoporosis progression in COPD patients was investigated. Methods: Forty-two COPD patients not on osteoporosis treatment for over 2 years were recruited. During follow-up, exacerbations had been prospectively recorded. Thoracic vertebral bone mineral density (BMD) was measured using chest CT, and the annual change in BMD was calculated. The change was compared between patients with and without a history of exacerbations. Results: The decrease in thoracic vertebral BMD was greater in patients with than in those without a history of exacerbations (median $\triangle B M D \mathrm{mg} / \mathrm{ml}$.year: -3.78 versus $-0.30, \mathrm{p}=$ 0.02 ). Moreover, multivariate regression analysis showed that exacerbations and baseline $\mathrm{PaO}_{2}$ were independent predictors of the BMD decrease $\left(\mathrm{R}^{2}=\mathbf{0 . 2 0}, \mathrm{p}=\right.$ 0.007 , and $R^{2}=0.09, p=0.03$, respectively) after adjustment for baseline age, smoking status, and airflow limitation. Conclusions: This is the first longitudinal study to demonstrate that COPD exacerbations are independently associated with osteoporosis progression. Osteoporosis progression should be evaluated in COPD patients, especially in those with a history of frequent exacerbations.
\end{abstract}

\section{Abbreviations}

BMD bone mineral density; BMI body mass index; COPD chronic obstructive pulmonary disease; CT computed tomography; $D_{\text {, }}$, diffusion capacity of carbon monoxide; ECLIPSE Evaluation of COPD Longitudinally to Identify

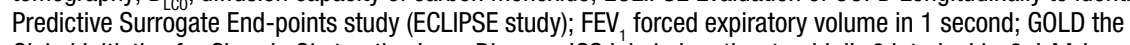
Global Initiative for Chronic Obstructive Lung Disease; ICS inhaled corticosteroid; IL-6 interleukin-6; LAA low attenuation area; $\mathrm{PaO}_{2}$ partial pressure of oxygen in arterial blood; RANKL, receptor activator of nuclear factor kappa-B ligand; ROI region of interest; TNF- $\alpha$ tumor necrosis factor $\alpha ; V_{A}$ alveolar ventilation; VCF vertebral compression fracture.

\section{Introduction}

The pathology of COPD involves not only the lungs but also extrapulmonary abnormalities such as diabetes, cachexia, skeletal muscle wasting, and anemia (1). Of these, osteoporosis is one of the most important abnormalities 
because it may cause vertebral compression fractures (VCF) that can deteriorate pulmonary function. It has been reported that the prevalence of VCF in COPD patients is high (24\% to 63\%) (2), and one compression fracture in the thoracic vertebra results in a $9 \%$ decrease in vital capacity and impairment in $\mathrm{FEV}_{1}$ in COPD patients $(3,4)$.

The common features in COPD patients, such as low body mass index (BMI), history of smoking, age, inactivity, systemic inflammation, and the use of systemic corticosteroids, are important risk factors for osteoporosis (3). Moreover, we previously reported that severity of emphysema was closely related to loss of vertebral bone mineral density (BMD) assessed by chest computed tomography (CT) scan (5), and our findings were subsequently confirmed by other investigators using conventional osteoporosis indices (Dual-emission X-ray absorptiometry) (6). These findings suggest that COPD pathology is closely linked to osteoporosis.

Exacerbation is an important issue in COPD because it has negative impacts on $\mathrm{FEV}_{1}(7,8)$, health status (9), survival $(10,11)$, the BODE index (12), and socioeconomic costs (13). Exacerbations also cause deterioration in several risk factors for osteoporosis, such as inactivity (12) and systemic inflammation (14), and the use of systemic corticosteroids during exacerbations may accelerate BMD loss (11). Moreover, we recently reported that exacerbations accelerated emphysematous change (15). Thus, we speculated that exacerbations may accelerate not only parenchymal destruction but also BMD loss. However, to the best of our knowledge, no longitudinal study has examined the relationship between COPD exacerbations and osteoporosis progression.

Using chest CT scan images, BMD of the thoracic vertebrae and emphysematous changes can be evaluated simultaneously $(16,17)$. Moreover, BMD of the vertebra assessed by chest CT scan is better than that assessed by dual X-ray absorption to predict vertebral VCFs (18). In the present study, the longitudinal impact of exacerbations on thoracic vertebral BMD was explored using chest CT scan data.

\section{Methods}

\section{Subjects}

This is a part of prospective observational study investigating COPD exacerbation $(12,15,19)$. The patient inclusion criteria were: (1) COPD diagnosed according to the criteria of the Global Initiative for Chronic Obstructive Lung Disease (1); and (2) the patient agreed to prospectively record exacerbations. The exclusion criteria were: (1) history of respiratory diseases other than COPD; (2) occurrence of malignancy within the previous 5 years; (3) history of bone disease; (4) receiving osteoporosis treatment such as bisphosphonates and alfacalcidol (vitamin $\mathrm{D}$ analogue); (5) currently receiving oral systemic corticosteroid therapy; (6) receiving rehabilitation during the study; and (7) receiving home-oxygen therapy.
The study protocol is summarized in Figure 1, and the details of patient disposition are provided in the result section. Briefly, from March 2006 to May 2008, we enrolled 82 of 104 patients with COPD who agreed to record exacerbations prospectively. The observation period was 2 years. Finally, follow-up CT scans were performed 2 years after study entry in 42 patients. The subject population in the present study was almost the same as in our previous study (15). The most notable difference between the two study populations was related to whether the patients receiving osteoporosis therapy were excluded. The ethics committee of Kyoto University approved the study (approval No. E182), and all patients provided their written informed consent to participate

\section{Exacerbation criteria and definition of stable condition}

Exacerbations were defined as symptomatic deterioration requiring medical treatment (antibiotics and/or systemic corticosteroids) $(15,19,20)$. Stable condition was defined as an exacerbation-free interval that lasted for more than 4 weeks. Symptomatic changes were assessed by a modified version of the East London cohort study criteria (7).

\section{Pulmonary function tests, CT acquisition, and calibration of CT numbers}

Baseline and 2-year follow-up CT scans (Aquilion 64; Toshiba, Tokyo, Japan; slice thickness, $0.5 \mathrm{~mm}$ ) and pulmonary function tests (Chestac-65V; Chest MI Corp, Tokyo, Japan) were performed under stable conditions. All pulmonary function tests and CT scans were performed after inhaling short-acting bronchodilators (salbutamol and ipratropium) as previously reported $(5,21)$. CT numbers in the lung field were corrected using tracheal air density to prevent the X-ray tube aging effect $(15,22)$.

\section{Analysis of low attenuation areas}

To evaluate pulmonary emphysema quantitatively, the low attenuation area percentage (LAA\%) was measured according to our previous reports $(5,23)$.

\section{Measurement of BMD in vertebral bone}

Using a modified method reported previously $(5,17)$, BMD was measured in the thoracic vertebral bones (T4, $\mathrm{T} 7, \mathrm{~T} 10)$ derived from the CT scan density. In a previous report, BMD was calculated using one chest $\mathrm{CT}$ scan slice, but in the present study, it was calculated using five chest CT scan slices. Briefly, first a mid-vertebral slice was selected using reconstructed images (sagittal and coronal images) from $0.5-\mathrm{mm}$ slice thickness CT images. Then, the elliptical region of interest (ROI) was encompassed manually as the largest possible area at

Copyright (C) 2012 Informa Healthcare USA, Inc 


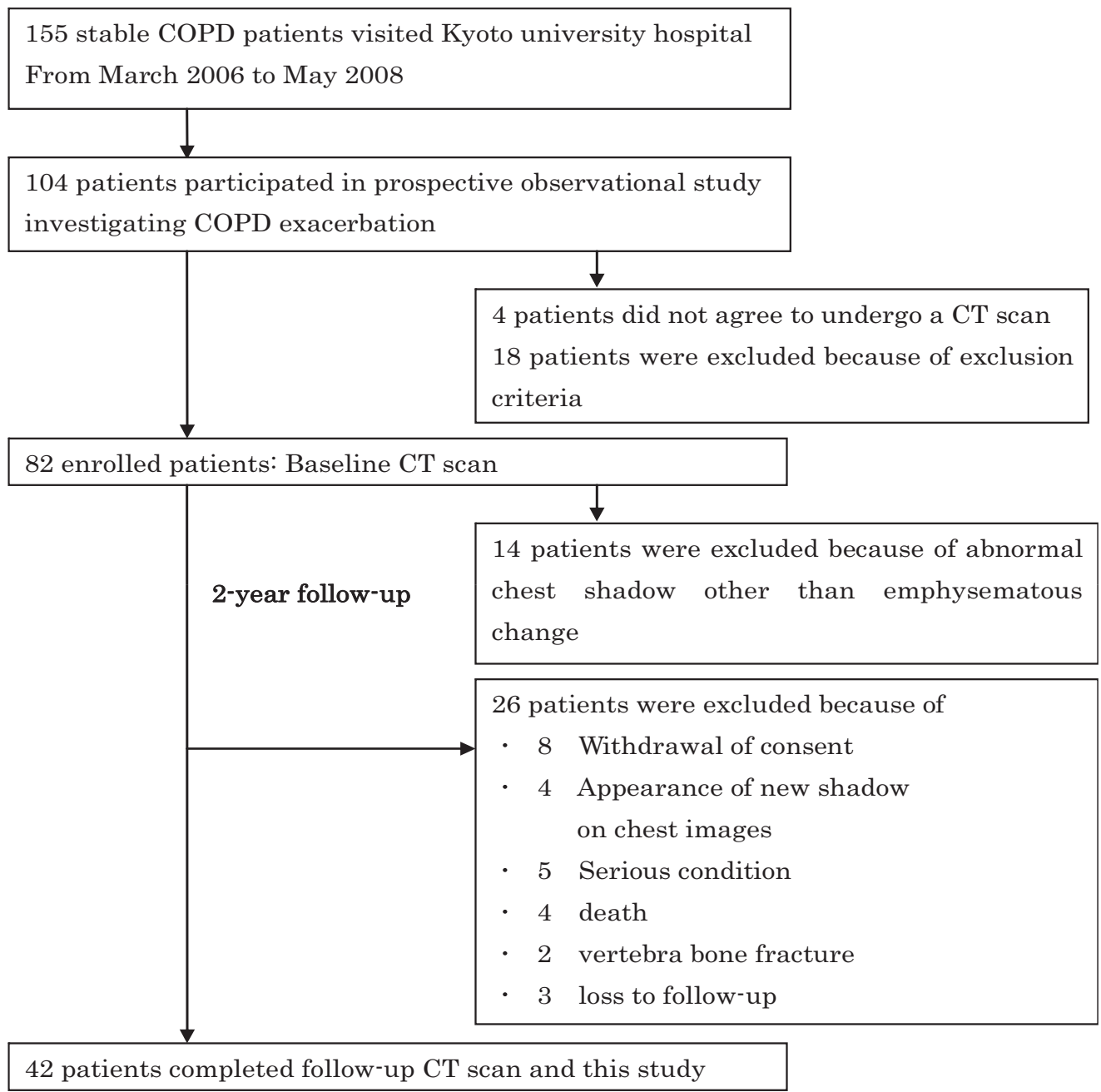

Figure 1. Patient disposition and reasons for exclusion. COPD, chronic obstructive pulmonary disease; CT, computed tomography.

the anterior portion of each vertebral body on five slices whose center was the chosen mid-vertebral slice.

Finally, the mean CT scan density of the ROI was measured. As in our previous report (5), BMD was calculated based on mean $\mathrm{CT}$ scan density using the formula (BMD (in milligrams per milliliter) $=0.767 \times \mathrm{CT}$ scan density (in $\mathrm{HU})+3.37$ ). This calculating formula was validated in our previous report using calibration phantom which contained eight tubes of known concentration of hydroxyapatite (5). All images were measured by two pulmonologists (H.K. and N.T.) to minimize interobserver variability of the measurements, and their measurements were then averaged to obtain final values.

\section{Measurement of the change in BMD}

The annual change in BMD $(\triangle \mathrm{BMD})$ was defined as follows:

$\triangle \mathrm{BMD}$ (in milligrams per milliliter per year )

$=(($ BMD after two-year follow-up $)-$

(BMD at baseline)) / (follow-up span (in years)).

Annual BMD percentage change normalized with baseline BMD was adjusted as follows: $\triangle \mathrm{BMD} /$ base (in percentage per year)

$=(\Delta \mathrm{BMD} /(\mathrm{BMD}$ at baseline $)) \times 100$

\section{Statistical analyses}

All statistical analyses were performed using JMP 7 software (SAS Institute; Cary, NC). The data are expressed as medians $\left(25^{\text {th }}, 75^{\text {th }}\right.$ percentile) unless otherwise indicated. The differences between groups were evaluated using the Mann-Whitney U-test. Data within groups were analyzed with the Wilcoxon signed-rank test. Relationships among data were assessed by Spearman's rank correlation test. To evaluate the relative contribution of exacerbations to the decrease in thoracic vertebral $\mathrm{BMD}$, multivariate regression analysis was performed. A $p$-value less than 0.05 was considered significant.

\section{Results}

\section{Patient characteristics}

Baseline CT scans were performed on 82 patients who had participated in our prospective observational study investigating $\operatorname{COPD}(15,19,20)$. Of these patients, 14 
were excluded because of abnormal chest shadows not associated with emphysematous changes seen on chest CT images at entry (Figure 1). Over the two-year followup, 26 patients were excluded for the following reasons: withdrawal of consent, appearance of a new shadow, serious condition, death, vertebral bone fracture, or lost to follow-up. Table 1 shows the characteristics of the study subjects (42 patients) who completed all of the follow-up examinations, including baseline and 2-year follow-up chest CT scans. During the observational period, 13 patients experienced exacerbations requiring treatment with antibiotics and/or systemic corticosteroids at least once, and 29 patients experienced no exacerbations. Of 13 patients with a history of exacerbations, only 1 patient received systemic corticosteroid treatment (methylprednisolone $16 \mathrm{mg} /$ day for 5 days). There were no significant differences in baseline clinical parameters, pulmonary function, $\mathrm{CT}$ parameters, or BMD between the groups (Table 2). Baseline pharmacological treatment including inhaled corticosteroids was not significantly different between the groups.

\section{Impact of exacerbations on BMD, lung functions, and emphysematous change}

Changes in BMD, lung functions, emphysematous change, and $\mathrm{PaO}_{2}$ between patients with and without a history of exacerbations are shown in Table 3. In patients who experienced exacerbations, BMD and BMD/base decreased significantly after the follow-up period, whereas these parameters did not change in patients who experienced no exacerbations. The median annual changes in BMD and BMD/base were significantly greater in patients with than in those without exacerbations $(\triangle B M D \mathrm{mg} / \mathrm{ml} \cdot y e a r:-3.78$ versus $-0.30, \mathrm{p}=0.01$, $\Delta \mathrm{BMD} /$ base $\%$ : -5.41 versus $-0.60, \mathrm{p}=0.02$ ) (Table 2 , Figure 2).

Table 1. Baseline characteristics of the study patients $(\mathrm{N}=42)$

\begin{tabular}{|c|c|c|}
\hline Characteristics & & Values \\
\hline Age & 70.0 & $(65.0,76.3)$ \\
\hline Gender, male : female & 39: & 3 \\
\hline Height, meter & 1.64 & $(1.60,1.69)$ \\
\hline Weight, $\mathrm{kg}$ & 57.5 & $(53.5,62.0)$ \\
\hline Body mass index & 21.0 & $(19.5,23.3)$ \\
\hline Smoking Status current : former & 13: & 39 \\
\hline Smoking history, pack-year & 53.5 & $(42.5,88.0)$ \\
\hline $\mathrm{FEV}_{1}, \mathrm{~L}$ & 1.61 & $(1.12,1.94)$ \\
\hline$\% \mathrm{FEV}_{1}, \%$ & 56.4 & $(41.8,69.4)$ \\
\hline LAA\% (-960), \% & 32.2 & $(25.0,38.1)$ \\
\hline $\mathrm{D}_{\mathrm{LCO}} N_{\mathrm{A}}, \mathrm{mL} / \mathrm{min} / \mathrm{mmHg} / \mathrm{L}$ & 2.61 & $(1.84,3.39)$ \\
\hline
\end{tabular}

Data are expressed as the median (25th, 75 th percentile). FEV , forced expiratory volume in 1 second; \% FEV, $\mathrm{FEV}_{1} \%$ predicted; LAA\%, percentage of low attenuation area; $\mathrm{D}_{\mathrm{LCO}} N_{\mathrm{A}}$, ratio of diffusing capacity to alveolar ventilation.
Table 2. Baseline characteristics of the two groups: Patients with and without a history of COPD exacerbations

\begin{tabular}{|c|c|c|c|c|c|}
\hline & \multicolumn{2}{|c|}{ Exacerbation (-) } & \multicolumn{2}{|c|}{ Exacerbation (+) } & \multirow[t]{2}{*}{$\mathrm{p}$-value } \\
\hline Subjects & & 29 & & 13 & \\
\hline Exacerbations/year & 0 & & 0.50 & $(0.48,0.83)$ & \\
\hline \multicolumn{6}{|l|}{$\begin{array}{l}\text { Baseline } \\
\text { characteristics }\end{array}$} \\
\hline Age, years & 66.0 & $(62.5,77.5)$ & 72.0 & $(68.0,74.0)$ & 0.27 \\
\hline $\begin{array}{l}\text { Gender, male : } \\
\text { female }\end{array}$ & 28: & 1 & 11: & 2 & 0.22 \\
\hline Body mass index & 21.6 & $(19.9,23.0)$ & 20.1 & $(17.7,24.3)$ & 0.24 \\
\hline $\begin{array}{l}\text { Smoking Status, } \\
\text { current : former }\end{array}$ & $11:$ & 18 & 2: & 11 & 0.28 \\
\hline $\begin{array}{l}\text { Smoking history, } \\
\text { pack-year }\end{array}$ & 57.0 & $(42.5,99.0)$ & 52.0 & $(41.5,78.8)$ & 0.57 \\
\hline $\mathrm{FEV}_{1}, \mathrm{~L}$ & 1.64 & $(1.12,2.08)$ & 1.45 & $(1.15,1.91)$ & 0.64 \\
\hline$\% \mathrm{FEV}_{1}, \%$ & 55.1 & $(39.3,72.3)$ & 61.0 & $(53.5,66.9)$ & 0.50 \\
\hline
\end{tabular}

GOLD

classification, $\mathrm{n}(\%)$

$\begin{array}{lccccc}\text { stage I } & 4 & (13.8) & 1 & (7.7) & \\ \text { stage II } & 14 & (48.3) & 10 & (76.9) & \\ \text { stage III } & 10 & (34.4) & 1 & (7.7) & \\ \text { stage IV } & 1 & (3.5) & 1 & (7.7) & \\ \text { BMD, mg/ml } & 132.4 & (100.0, & 135.8 & (110.1, & 0.46 \\ & & 152.4) & & 166.5) & \\ \text { AA\% (-960), \% } & 31.8 & (24.9,38.1) & 32.6 & (24.9,39.2) & 0.87 \\ \mathrm{LLC}_{\mathrm{A}} \mathrm{N}_{\mathrm{A}}, \mathrm{mL} / \mathrm{min} / & 2.68 & (1.86,3.36) & 2.48 & (1.43,3.88) & 0.59 \\ \mathrm{mmHg}^{2} & & & & & \\ \mathrm{~Pa}_{2}, \mathrm{mmHg} & 78.9 & (73.4,84.2) & 73.7 & (70.7,85.9) & 0.64 \\ \mathrm{CS}_{\text {, Yes:No }} & 4: & 25 & 4: & 9 & 0.23 \\ \mathrm{io}, \text { Yes:No } & 12: & 17 & 5: & 8 & 1.00\end{array}$

Data are expressed as the median (25th, 75th percentile). $\mathrm{FEV}_{1}$, forced expiratory volume in 1 second; \%FEV ${ }_{1}, \mathrm{FEV}_{1} \%$ predicted; GOLD, The Global Initiative for Chronic Obstructive Lung Disease; BMD, bone mineral density; LAA\%, percentage of low attenuation area LAA\%, percentage of low attenuation area; $D_{\text {Coc }} N$, ratio of diffusing capacity to alveolar ventilation ICS, ihhaled corticosteroid; Tio, tiotropium.

In agreement with our previous report (15), LAA\% also increased significantly after the observation period in patients who experienced exacerbations $(\mathrm{p}=0.01)$ (Table 3), whereas this parameter did not change in patients who experienced no exacerbations. There were no significant annual changes in pulmonary function test results such as $\mathrm{FEV}_{1}$ and $\mathrm{D}_{\mathrm{LCO}}$ between the groups.

Table 4 shows the correlation between the annual change in BMD and associated factors for osteoporosis (exacerbation frequency and factors that have been shown to be associated with osteoporosis). The annual change in BMD was significantly correlated with the exacerbation frequency (Spearman's rank correlation coefficient $\rho=-0.37, p=0.02$ ). On univariate analysis, baseline $\mathrm{FEV}_{1}$ was associated with the change in BMD $(\mathrm{p}=0.04)$ whereas other factors such as BMI, smoking history, \%FEV ${ }_{1}$ predict, and LAA\% were not.

On stepwise multivariate regression analysis (Table 5) to examine the relative contribution of each variable to 
Table 3. Annual changes in thoracic vertebral BMD, lung function, and LAA\%

\begin{tabular}{|c|c|c|c|c|c|c|c|}
\hline \multirow[b]{2}{*}{$\mathrm{BMD}, \mathrm{mg} / \mathrm{ml}$} & \multicolumn{2}{|c|}{ Exacerbation (-) } & \multirow{2}{*}{$\frac{\mathrm{p} \text {-value (within group) }}{0.41}$} & \multicolumn{2}{|c|}{ Exacerbation (+) } & \multirow{2}{*}{$\frac{p \text {-value (within group) }}{0.002}$} & \multirow{2}{*}{$\frac{\mathrm{p} \text {-value (between groups) }}{0.01}$} \\
\hline & -0.30 & $(-1.82,1.33)$ & & -3.78 & $(-5.81,-0.29)$ & & \\
\hline BMD/base, $\%$ & -0.60 & $(-3.07,2.63)$ & 0.39 & -5.41 & $(-10.6,-0.36)$ & 0.002 & 0.02 \\
\hline BMI & 0.00 & $(-0.53,0.38)$ & 0.65 & -0.78 & $(-1.49,0.70)$ & 0.34 & 0.38 \\
\hline $\mathrm{FEV}_{1}, \mathrm{~mL}$ & -51.4 & $(-117.0,-7.7)$ & 0.0001 & -75.0 & $(-97.9,-4.7)$ & 0.0005 & 0.72 \\
\hline$\% \mathrm{FEV}_{1}, \%$ & 0.28 & $(-2.08,2.15)$ & 0.74 & 0.00 & $(-1.72,1.58)$ & 0.91 & 0.85 \\
\hline $\begin{array}{l}\mathrm{D}_{\mathrm{LCO}} N_{\mathrm{A}}, \mathrm{mL} / \mathrm{min} / \\
\mathrm{mmHg} / \mathrm{L}\end{array}$ & -0.13 & $(-0.32,0.03)$ & 0.01 & -0.15 & $(-0.26,0.03)$ & 0.10 & 1.00 \\
\hline LAA\% $(-960), \%$ & 0.12 & $(-0.61,1.27)$ & 0.43 & 1.32 & $(-4.78,1.31)$ & 0.0005 & 0.01 \\
\hline $\mathrm{PaO}_{2}, \mathrm{mmHg}$ & -0.48 & $(-2.42,1.80)$ & 0.91 & -1.00 & $(-4.78,1.32)$ & 0.20 & 0.29 \\
\hline
\end{tabular}

Data are expressed as the median (25th, 75 th percentile). BMD, bone mineral density in thoracic vertebrae; BMD/base, percentage change in BMD compared with baseline BMD; FEV ${ }_{1}$, forced expiratory volume in 1 second; $\% \mathrm{FEV}_{1}, \mathrm{FEV}_{1} \%$ predicted $\mathrm{D}_{\mathrm{Lco}} \mathrm{N}_{\mathrm{A}}$, ratio of diffusing capacity to alveolar ventilation; LAA\%, percentage of low attenuation area.

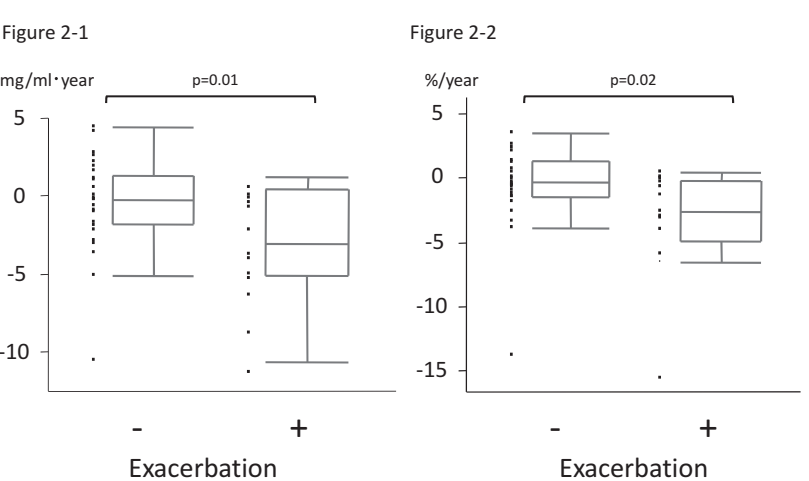

Figure 2. Annual change in thoracic vertebral BMD in patients without / with a history of exacerbations. Figure 2-1 Annual absolute change in thoracic vertebral $B M D$ in patients without / with a history of exacerbations $(\triangle B M D(\mathrm{mg} / \mathrm{ml} \cdot$ year): -0.30 versus $-3.78, p=0.01$ ). Figure 2-2. Annual percentage change in thoracic vertebral BMD in patients without / with a history of exacerbations based on baseline BMD. ( $\triangle \mathrm{BMD} / \mathrm{base}(\mathrm{mg} / \mathrm{ml} \cdot$ year): -0.60 versus $-5.41, \mathrm{p}=0.02)$. The horizontal line is the median value, the box is the interquartile range, and the whiskers indicate the range, excluding outlying and extreme values (i.e., points with values $\geq 1.5$ box lengths from the upper or lower limits of the box). BMD, bone mineral density; $\triangle \mathrm{BMD}$, annual change in thoracic $\mathrm{BMD} ; \triangle \mathrm{BMD} /$ base, annual percentage change in BMD based on baseline BMD.

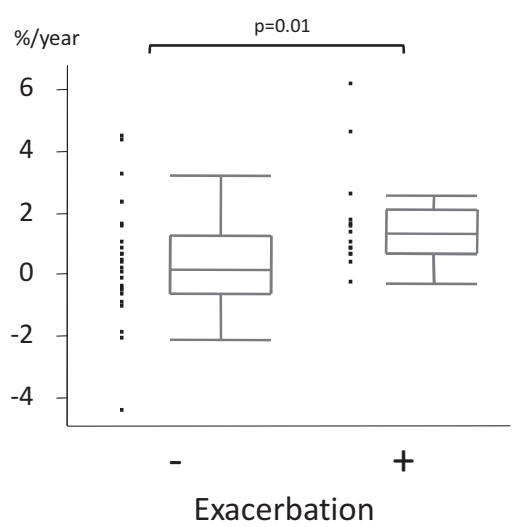

Figure 3. Annual emphysematous change represented as $L A A \%$ on $C T$ in patients without / with a history of exacerbations. (LAA (\%): 0.12 versus $1.32, p=0.01$ ) The horizontal line is the median value, the box is the interquartile range, and the whiskers indicate the range, excluding outlying and extreme values (i.e., points with values $\geq 1.5$ box lengths from the upper or lower limits of the box). LAA, low attenuation area; CT, computed tomography.

predict the change in BMD, 5 factors that ranked in the top 5 on univariate analysis were selected as candidate explanatory variables (exacerbation, age, smoking index, $\mathrm{FEV}_{1}$, and $\mathrm{PaO}_{2}$ ). As a result, exacerbation and baseline $\mathrm{PaO}_{2}$ were included in this model as explanatory variables after stepwise variable selection $\left(R^{2}=0.20, p=0.007\right.$, and $\mathrm{R}^{2}=0.09, \mathrm{p}=0.03$, respectively).

\section{Discussion}

In the present study, the analysis showed that a decrease in thoracic vertebral BMD was significantly associated with COPD exacerbations and baseline $\mathrm{PaO}_{2}$, while other factors known as risk factors for osteoporosis were not associated with the annual change in thoracic vertebral BMD. To the best of our knowledge, this is the first longitudinal study that investigated the impact of exacerbations on comorbidity in COPD patients.

In COPD patients, various risk factors, such as low BMI, smoking, age, inactivity, systemic inflammation, use of systemic corticosteroids (3), and LAA\%, can be associated with osteoporosis (5). Although most of them are still controversial, only LAA\% $(5,6)$ and BMI $(5,24)$ has been confirmed to correlate with BMD in cross-sectional studies. Osteoporosis is known as one of the common systemic manifestations in COPD (3), but the pathogenesis of osteoporosis in COPD patients has not been fully understood. Considering our result that the exacerbation frequency was significantly correlated with the decrease in thoracic vertebral BMD, the factors involved in exacerbations could be precipitating key factors and cause the adverse effect.

Of these factors, systemic inflammation is thought to play an important role in the progression of osteoporosis in COPD patients $(3,25)$. In fact, tumor necrosis factor $\alpha$ (TNF- $\alpha$ ) and interleukin-6 (IL-6) have been reported to be associated with osteoporosis in COPD patients (26), and both factors are known to stimulate osteoclasts and increase bone resorption through RANKL-mediated bone resorption in vitro (27). In patients with exacerbations, the levels of various proinflammatory markers, such as IL-6, were reported to be elevated (14). The elevated systemic inflammatory markers, especially TNF- $\alpha$ and IL-6, in patients with 
Table 4. Univariate associations with annual change in thoracic vertebral BMD

\begin{tabular}{|c|c|c|}
\hline Variables & $\begin{array}{l}\text { Spearman's rank } \\
\text { correlation }(\rho)\end{array}$ & $\mathrm{p}$-value \\
\hline \multicolumn{3}{|l|}{ Baseline characteristics } \\
\hline Age & -0.18 & 0.26 \\
\hline Body mass index & -0.04 & 0.80 \\
\hline Smoking history & 0.20 & 0.20 \\
\hline $\mathrm{FEV}_{1}$ absolute & 0.32 & 0.04 \\
\hline \%FEV1 predict & 0.11 & 0.49 \\
\hline $\mathrm{D}_{\mathrm{LCO}} / N_{\mathrm{A}}$ & 0.16 & 0.30 \\
\hline LAA\% $(-960)$ & 0.03 & 0.86 \\
\hline $\mathrm{PaO}_{2}$ & 0.29 & 0.07 \\
\hline \multicolumn{3}{|l|}{ Annual change } \\
\hline Frequency of excerbation & -0.37 & 0.02 \\
\hline$\Delta \mathrm{FEV}_{1}$ & -0.16 & 0.32 \\
\hline$\Delta \% \mathrm{FEV}_{1}$ & 0.00 & 0.98 \\
\hline$\Delta \mathrm{BMI}$ & 0.05 & 0.75 \\
\hline$\Delta \mathrm{LAA} \%(-960)$ & -0.10 & 0.53 \\
\hline$\Delta \mathrm{PaO}_{2}$ & 0.22 & 0.20 \\
\hline
\end{tabular}

Relationships were assessed by Spearman's rank correlation test. BMD, bone mineral density; $\mathrm{FEV}_{1}$, forced expiratory volume in 1 second; $\% \mathrm{FEV}_{1}, \mathrm{FEV}, \%$ predicted; $\mathrm{D}_{1} N_{\mathrm{A}}$ ratio of diffusing capacity to alveolar ventilation; $L A \%$, percentage of low attenuation area $\Delta$ means annual change in each variables.

Table 5. Stepwise multivariate regression analysis showing the relative contribution of each variable to predict the change in BMD

\begin{tabular}{lccc}
\hline & Coefficient & p-value & $\mathrm{R}^{2}$ \\
\hline Intercept & -0.094 & & \\
History of exacerbations, yes:no & -0.013 & 0.007 & 0.20 \\
$\mathrm{PaO}_{2}, \mathrm{mmHg}$ & 0.001 & 0.03 & 0.09 \\
Cumulative $^{2}$ & & & 0.30
\end{tabular}

Exacerbation (two categories: the presence versus absence of a history of exacerbations), age, smoking history, baseline $\mathrm{FEV}$, and $\mathrm{PaO}_{2}$ were included as candidate tions), age, smoking history, baseline $\mathrm{FEV}_{1}$, and $\mathrm{PaO}_{2}$ were included as candidate
independent variables. After stepwise variable selection, baseline factors (age, smoking history and $\mathrm{FEV}_{1}$ ) were excluded.

exacerbations might have caused the deterioration in BMD in the present study. Further study is necessary to explore these ideas.

It has been suggested that use of systemic steroids during exacerbations is one of the precipitating factors, but in the present study, only 1 of 13 patients with a history of exacerbations received systemic corticosteroid treatment. Even excluding this case, the study yielded the same conclusion. Thus, in clinical practice, it is important to pay attention to the patients who have a history of frequent exacerbations and treat them because they have a greater risk for osteoporosis progression, even if they do not receive systemic corticosteroids during exacerbations.

Multivariate analysis revealed that baseline $\mathrm{PaO}_{2}$ was associated with the BMD decline independently of a his- tory of exacerbations. Although no studies have shown that hypoxemia is associated with osteoporosis, baseline hypoxemia may reflect the patients' dyspnea that causes inactivity, a risk factor for osteoporosis. Alternately, hypoxemia itself has adverse effects on osteoporosis in COPD patients (28). To confirm this finding and causal association, information about dyspnea and activity should be assessed in a future study.

We performed a preliminary study of the effect of osteoporosis therapy on the change in thoracic vertebral BMD. To explore the effect of osteoporosis therapy on BMD, we measured the change in BMD in 18 patients with a history of exacerbations using the same method as in the present study (online supplement e-Table 1). Osteoporosis therapy significantly improved the decrease in BMD compared to no osteoporosis therapy in patients with a history of exacerbations $(\mathrm{p}=0.002$, online supplement e-Table 2). These results suggest the potential of osteoporosis therapy, especially in patients with a history of exacerbations. This finding should be investigated in a future study.

This study had several limitations. First, the sample size was small. However, this was a single center study using only one scanner, so that the instability of CT scanners was less problematic than in multicenter studies.

In addition, exacerbations were prospectively recorded by at least two respiratory physicians who were unaware of CT data. These advantages were thought sufficient to overcome the small sample size. Moreover, one large observational study, the Evaluation of COPD Longitudinally to Identify Predictive Surrogate End-points study (ECLIPSE study), showed that the co-existence of osteoporosis was associated with the occurrence of exacerbations in a cross-sectional cohort (29). However, they did not examine the influence of exacerbations on osteoporosis progression. The findings in the present longitudinal study further deepen our understanding of the relationship between COPD exacerbations and osteoporosis progression that ECLIPSE suggested. In the present study we could detect the progression of LAA in those who have a history of exacerbations, but couldn't detect the decline in $\mathrm{FEV}_{1}$. It is partly because this study was small sample study.

Second, BMD in the present study was calculated on the chest CT data using our formula that was validated in our previous report (5). The data of the present study did not include Dual Energy X-ray Absorptiometry (DEXA), which is the standard method to estimate BMD. The lack of DEXA data could be a limitation, but it has been reported that $\mathrm{CT}$ scan density showed a highly significant positive correlation with pathological measurements of vertebral bone density (30). As described in the introduction section BMD of the vertebra assessed by chest CT scan is clinically useful to predict vertebral compression fractures that could deteriorate pulmonary functions. Moreover, chest CT scan can detect emphysematous change (LAA) and BMD simultaneously without additional X-ray exposure by DEXA. 
Third the data of the present study subjects lack some confounding factors that could affect BMD, for example activity, diet intake (calcium and vitamin D intake), and loss of fat-free mass, since it has been suggested that inactivity could cause osteoporosis in COPD patients (31). The present study did not include some markers of bone metabolism (for example values for 25-hydroxyvitamin D) and systemic inflammation either. Future research is needed to assess the effect of other factors that were lacking in the present study and to clarify the mechanism of osteoporosis progression with COPD exacerbations.

\section{Conclusions}

In conclusion, the present study demonstrated that the decrease in thoracic vertebral BMD was greater in patients with a history of exacerbations than in those without a history of exacerbations. These data suggest that osteoporosis progression should be evaluated in COPD patients, especially in those with a history of frequent exacerbations.

\section{Acknowledgments}

Hirofumi Kiyokawa contributed to the study design, collection of data, analysis and interpretation of data, and writing the manuscript. Shigeo Muro contributed to the study design, collection, analysis and interpretation of data, editing the manuscript, and the acquisition of funding, and takes responsibility for the integrity of the work as a whole, from inception to publication. Tsuyoshi Oguma developed the custom-made application used to analyze the CT data, and contributed to data interpretation and editing the manuscript. Susumu Sato contributed to the study design, data collection and analysis. Naoya Tanabe contributed to the study design, data collection and analysis. Tamaki Takahashi contributed to the study design, data collection and analysis. Megumi Kudo contributed to the study design, data collection and analysis. Daisuke Kinose contributed to the study design, data collection and analysis. Hiroshi Kondoh contributed to the study design, data collection and analysis. Takeshi Kubo contributed to the study design, data collection and analysis. Yuma Hoshino contributed to the study design, data collection and analysis. Emiko Ogawa contributed to the study design, data collection and analysis. Toyohiro Hirai contributed to the study design, data collection and analysis. Michiaki Mishima contributed to the study design, data analysis and interpretation, editing the manuscript and funding acquisition.

\section{Declaration of interest}

We declare that there is no potential conflict of interest associated with this manuscript.

\section{References}

1. Rondriguez-Roisin R. Global strategy for Diagnosis, Management, and Prevention of COPD (UPDATED 2010). http://wwwgoldcopdcom2011 December 2010.

2. Jorgensen NR, Schwarz P, HolmeI, The prevalence of osteoporosis in patients with chronic obstructive pulmonary disease: a cross-sectional study. Respir Med 2007 Jan; 101(1):177-185, McEvoy CE, Ensrud KE, Bender E, et al. Association between corticosteroid use and vertebral fractures in older men with chronic obstructive pulmonary disease. Am J Respir Crit Care Med 1998 Mar; 157(3 Pt 1):704-709.

3. Lehouck A, Boonen S, Decramer M, COPD, bone metabolism, and osteoporosis. Chest $2011 \mathrm{Mar} ; 139(3): 648-657$.

4. Harrison RA, Siminoski K, Vethanayagam D, Osteoporosisrelated kyphosis and impairments in pulmonary function: a systematic review. J Bone Miner Res 2007 Mar; 22(3):447457.

5. Ohara T, Hirai T, Muro S, Relationship between pulmonary emphysema and osteoporosis assessed by $\mathrm{CT}$ in patients with COPD. Chest 2008 Dec; 134(6):1244-1249.

6. Bon J, Fuhrman CR, Weissfeld JL, Radiographic emphysema predicts low bone mineral density in a tobacco-exposed cohort. Am J Respir Crit Care Med 2011 Apr 1; 183(7):885-890.

7. Donaldson GC, Seemungal TA, Bhowmik A, Relationship between exacerbation frequency and lung function decline in chronic obstructive pulmonary disease. Thorax 2002 Oct; 57(10):847-852.

8. Kanner RE, Anthonisen NR, Connett JE. Lower respiratory illnesses promote $\mathrm{FEV}$, decline in current smokers but not ex-smokers with mild chronic obstructive pulmonary disease: results from the lung health study. Am J Respir Crit Care Med 2001 Aug 1; 164(3):358-364.

9. Seemungal TA, Donaldson GC, Paul EA, Effect of exacerbation on quality of life in patients with chronic obstructive pulmonary disease. Am J Respir Crit Care Med 1998 May; 157(5 Pt 1):1418-1422.

10. Gunen H, Hacievliyagil SS, Kosar F, Factors affecting survival of hospitalised patients with COPD. Eur Respir J 2005 Aug; 26(2):234-241.

11. Connors AF, Jr., Dawson NV, Thomas C, Outcomes following acute exacerbation of severe chronic obstructive lung disease. The SUPPORT investigators (Study to Understand Prognoses and Preferences for Outcomes and Risks of Treatments). Am J Respir Crit Care Med 1996 Oct; 154(4 Pt 1):959-967.

12. Cote CG, Dordelly LJ, Celli BR. Impact of COPD exacerbations on patient-centered outcomes. Chest 2007 Mar;131(3):696704.

13. Wouters EF. The burden of COPD in The Netherlands: Results from the confronting COPD survey. Respir Med 2003 Mar; 97 Suppl C:S51-59.

14. Groenewegen KH, Dentener MA, Wouters EF. Longitudinal follow-up of systemic inflammation after acute exacerbations of COPD. Respir Med 2007 Nov; 101(11):2409-2415.

15. Tanabe N, Muro S, Hirai $\mathrm{T}$, Impact of exacerbations on emphysema progression in Chronic Obstructive Pulmonary Disease. Am J Respir Crit Care Med 2011 Mar 11.

16. Kalender WA, Klotz E, Suess C. Vertebral bone mineral analysis: an integrated approach with CT. Radiology 1987 Aug; 164(2):419-423, Weishaupt D, Schweitzer ME, DiCuccio $\mathrm{MN}$, et al. Relationships of cervical, thoracic, and lumbar bone mineral density by quantitative CT. J Comput Assist Tomogr 2001 Jan-Feb; 25(1):146-150.

17. Steiger P, Block JE, Steiger S, Spinal bone mineral density measured with quantitative CT: Effect of region of interest, vertebral level, and technique. Radiology 1990 May; 175(2):537-543.

18. Rehman Q, Lang T, Modin G, Quantitative computed tomography of thelumbar spine, not dual X-ray absorptiometry, 
is an independent predictor of prevalent vertebral fractures in postmenopausal women with osteopenia receiving long-term glucocorticoid and hormone-replacement therapy. Arthritis Rheum 2002 May; 46(5):1292-1297.

19. Terada K, Muro S, Ohara T, Abnormal swallowing reflex and COPD exacerbations. Chest 2010 Feb; 137(2):326-332,Terada $\mathrm{K}$, Muro S, Ohara T, et al. Cough-reflex sensitivity to inhaled capsaicin in COPD associated with increased exacerbation frequency. Respirology 2009 Nov; 14(8):1151-1155.

20. Terada K, Muro S, Sato S, Impact of gastro-oesophageal reflux disease symptoms on COPD exacerbation. Thorax 2008 Nov; 63(11):951-955.

21. Ogawa E, Nakano Y, Ohara T, Body mass index in male patients with COPD: correlation with low attenuation areas on CT. Thorax 2009 Jan; 64(1):20-25.

22. Ohara T, Hirai T, Sato S, Longitudinal study of airway dimensions in chronic obstructive pulmonary disease using computed tomography. Respirology 2008 May; 13(3):372378.

23. Mishima $\mathrm{M}$, Hirai $\mathrm{T}$, Itoh $\mathrm{H}$, Complexity of terminal airspace geometry assessed by lung computed tomography in normal subjects and patients with chronic obstructive pulmonary disease. Proc Natl Acad Sci USA 1999 Aug 3; 96(16):8829-8834.
24. Graat-Verboom L, van den Borne BE, Smeenk FW, Osteoporosis in COPD outpatients based on bone mineral density and vertebral fractures. J Bone Miner Res 2011 Mar; 26(3):561-568.

25. Biskobing DM. COPD and osteoporosis. Chest 2002 Feb; 121(2):609-620.

26. Bolton CE, Ionescu AA, Shiels KM, Associated loss of fatfree mass and bone mineral density in chronic obstructive pulmonary disease. Am J Respir Crit Care Med 2004 Dec 15; 170(12):1286-1293.

27. Hardy R, Cooper MS. Bone loss in inflammatory disorders. J Endocrinol 2009 Jun; 201(3):309-320.

28. Agusti AG. Systemic effects of chronic obstructive pulmonary disease. Proc Am Thorac Soc 2005; 2(4):367-370; discussion 71-72.

29. Hurst JR, Vestbo J, Anzueto A, Susceptibility to exacerbation in chronic obstructive pulmonary disease. N Engl J Med 2010 Sep 16; 363(12):1128-1138.

30. McBroom RJ, Hayes WC, Edwards WT, Prediction of vertebral body compressive fracture using quantitative computed tomography. J Bone Joint Surg Am 1985 Oct; 67(8):1206-1214.

31. Jorgensen NR, Schwarz P. Osteoporosis in chronic obstructive pulmonary disease patients. Curr Opin Pulm Med 2008 Mar; 14(2):122-127. 